\title{
Desastres como indícios da crise do capitalismo?
}

\author{
Disasters as signs of the crisis of capitalism? \\ ¿Los desastres como signos de la crisis del capitalismo?
}

Allan Lavell

\section{Resumo}

LAVELL, A. Desastres como indícios da crise do capitalismo? Rev. C\&Trópico, v. 45, n. 2, p. 79-88, 2021. DOI: https://doi.org/10.33148/cetropicov45n2(2021)art5

O artigo trata da polêmica questão: seriam os desastres indícios da crise do capitalismo? O capitalismo passou por múltiplos estágios ao longo da história e, em sua última fase, mais global, temos o neoliberalismo que, dos anos $1980 \mathrm{em}$ diante, se desenvolve em resposta ao keynesianismo e ao estado de bem-estar. Mas esse neoliberalismo tem expressões e relações com outras facetas como a globalização, o capitalismo financeiro e continua em transição para o que hoje se chama de capitalismo cibernético. Assim, a questão dos desastres como indicadores de crise exige que desagreguemos o significado e a realidade do neoliberalismo como prática. E depois disso, é preciso relacioná-lo com os fatores de risco que emergem na prática dessa ideologia particular em termos de economia. E, então, ter a habilidade de entender como o risco foi construído e, consequentemente, quando esse risco atinge as condições do desastre dado, qual seu papel e como ele indica relação com a crise do capitalismo, baseando-se na compreensão do processo de construção social do risco.

Palavras-chave: Capitalismo, crise, desastres sistêmicos, construção social do risco.

\section{Abstract}

LAVELL, A. Disasters as signs of the crisis of capitalism? Rev. C\&Trópico, v. 45, n. 2, p. 79-88, 2021. DOI: https://doi.org/10.33148/cetropicov45n2(2021)art5

The article deals with the controversial question: are disasters signs of the crisis of capitalism? Capitalism has gone through multiple stages throughout history and in its last, more global phase, we have neoliberalism which, from the 1980s onwards, developed in response to Keynesianism and the welfare state. But this neoliberalism has expressions and relationships with other facets such as globalization, financial

1 Geógrafo pela London School of Economics and Political Science (LSE). Atualmente, coordenador do "Programa de Estudos Sociais de Risco de Desastres e Adaptação a Mudanças Climáticas" no Escritório do Secretariado Geral da Faculdade Latino Americana de Ciências Sociais (FLACSO) em San Jose, Costa Rica. Membro-fundador da Rede Latino-americana para Estudos Sociais de Prevenção de Desastres (LA RED) onde foram publicados os primeiros trabalhos sobre desnaturalização dos desastres. E-mail: allanmlavell@gmail.com Orcid: https://orcid.org/0000-0001-5653-0287 
capitalism and continues in transition to what is now called cybernetic capitalism. Thus, the issue of disasters as indicators of crisis demands that we disaggregate the meaning and reality of neoliberalism as a practice. And after that, it is necessary to relate it to the risk factors that emerge in the practice of this particular ideology in terms of economics. And so having the ability to understand how the risk was constructed and, consequently, when that risk reaches the conditions of the given disaster, what is its role and how it indicates its relationship with the crisis of capitalism, based on an understanding of the process of social construction of risk.

Keywords: Capitalism, crisis, systemic disasters, social construction of risk.

\section{Resumen}

LAVELL, A. ¿Los desastres como signos de la crisis del capitalismo? Rev. CઐTrópico, v. 45, n. 2, p. 79-88, 2021. DOI: https://doi.org/10.33148/cetropicov45n2(2021)art5

El artículo aborda la controvertida cuestión: ¿son los desastres signos de la crisis del capitalismo? El capitalismo ha pasado por múltiples etapas a lo largo de la historia y en su última fase, más global, tenemos al neoliberalismo que, a partir de la década de 1980, se desarrolló como respuesta al keynesianismo y al estado de bienestar. Pero este neoliberalismo tiene expresiones y relaciones con otras facetas como la globalización, el capitalismo financiero y continúa en transición hacia lo que ahora se llama capitalismo cibernético. Así, el tema de los desastres como indicadores de crisis exige desagregar el significado y la realidad del neoliberalismo como práctica. $Y$ después de eso, es necesario relacionarlo con los factores de riesgo que surgen en la práctica de esta ideología particular en términos económicos. Y así, tener la capacidad de comprender cómo se construyó el riesgo y, en consecuencia, cuándo ese riesgo llega a las condiciones del desastre dado, cuál es su rol y cómo indica su relación con la crisis del capitalismo, basado en una comprensión del proceso de construcción social del riesgo.

Palabras clave: Capitalismo. Crisis. Desastres sistémicos. Construcción social del riesgo. 


\section{Desnaturalizar Desastres}

Apesar das insistências, faz pelo menos 30 anos que me dedico ao tema de risco e desastre, ainda não conseguimos desnaturalizar os desastres no discurso de atores fundamentais internacionais e nacionais. Assim, embora pareça redundante a necessidade de insistir, ela também se torna importante, porque atrás dessa resistência à mudança, há razões profundas que devem ser investigadas para chegar a uma compreensão mais refinada e completa sobre o que é a questão mais geral do desastre e seus antecedentes, no que se refere ao risco.

Primeiro, gostaria de dizer que sou fascinado pelo tema que de alguma forma enfatiza no que chamei de interpretações e significados de risco e desastres em oposição à análise de impactos futuros sobre as sociedades (que, obviamente, permanecem importantes). Lembro-me de quando fui especialista em desenvolvimento urbano e regional até o final dos anos 80 e essa tinha sido minha principal área de preocupação acadêmica, ativa e pedagógica. Lidei com a questão do risco e desastre, e muitos amigos na América Latina, no México, onde trabalhava, me disseram: O que você vai fazer com uma questão humanitária? Por que você vai trabalhar com problemas de respostas a desastres, pois o tema não parece relevante para o desenvolvimento de seu mundo acadêmico? E me lembro que época disse: não, não vou produzir um tópico. Vou trabalhar um tema completo, informado a partir de perguntas sobre desenvolvimento, particularmente: qual o significado central e sentido de um desastre? Não o que é ou como como é expresso. Mas sim, qual é o seu significado central? A pergunta e a resposta que me fiz naquela época foi que, para mim, desastres, como os entendíamos - principalmente como ameaças naturais e a concretude das condições de um desastre -, era uma discussão que representava o ponto mais alto da relação desequilibrada entre a sociedade e o meio ambiente que lhe sustentava. $\mathrm{O}$ desastre era o ponto mais alto de uma relação desigual que só poderia levar a impactos severos na sociedade. E essa diferença de medição do impacto e do tipo de análise foi o que compreendemos ser importante.

Assim, o tema geral do seminário nos convida a refletir sobre significados mais profundos. Para mim, era quase óbvio que estávamos procurando por alguém que veio da ciência integrada, de atitudes mais holísticas e estudos mais abrangentes de fenômenos relacionado ao assunto em questão, porque não foi difícil, desde o início, entender que o problema do risco e do desastre, era um problema da sociedade, não da natureza. No entanto, percebe-se que para muitas pessoas é um problema aceitar o que parece tão óbvio e simples. Acredito que hoje, a nova geração de pesquisadores, e temos discutido isso no âmbito de La RED (ver www.desenredando.org), tem um enorme desafio de pesquisa, que é extremamente mais complexo do que o que enfrentamos em anos anteriores.

Isso me faz pensar que não tenho uma resposta para a questão desta mesa: seriam os desastres indícios da crise do capitalismo? Não tenho as armas metodológicas, nem as empíricas, nem os dados, nem a pesquisa que sustenta um argumento de que desastres são uma indicação da crise do capitalismo, e essa confusão na minha mente, 
é porque quem é um? E as armas metodológicas, científicas e disciplinares que empunho? Não sou economista. Se eu tivesse que entrar na teoria da crise, com Marx por exemplo, em que a taxa de lucro de ascendente está naturalmente associada com o desenvolvimento do capital, me perco mais do que no insinuado, no simples e superficial.

Então, realmente, para entendê-la, é preciso delimitar historicamente a crise e é preciso entender os motivos que impulsionam a crise e depois relacionar esses motivos com o que é a construção de um risco na sociedade. E isso é mencionado sem questionar o título da mesa, pois o título é absolutamente fundamental e deve ser um convite para futuras pesquisas. Mas associadas com essa dúvida, há também a dúvida se os desastres também representam a crise dos modelos de socialismo e comunismo que temos visto nos últimos 50 anos. Estou falando de modelos, porque não temos nem socialismo nem comunismo, e hoje talvez a China seja mais capitalista que os Estados Unidos. Não sei, não vou emitir critérios.

Porém, a questão pode ser reformulada: os desastres representam a crise dos modelos de desenvolvimento em geral, formuladas sob certos princípios que contradizem o que estão falando hoje sobre a economia verde, a economia azul, a economia sustentável e outras? Por isso, crio uma série de perguntas que derivam do título porque não sou capaz de responder ou por causa de deficiências metodológicas, científicas, teóricas, devido à ausência de dados e porque me parece que a questão poderia ser estendida para cobrir outros elementos. No entanto, a questão é fundamental e de onde ela deriva é fundamental. Por isso no pouco espaço que tenho, vou fazer como o aluno que sendo convidado a escrever sobre o sistema esquelético do ser humano em um exame, começa dizendo que sistema esquelético é a base do sistema muscular e, então, começa a falar sobre o sistema muscular. Vou fazer algo parecido. Quero dizer, não vou falar sobre a questão da crise como uma indicação. Falarei sobre as condições do capitalismo em suas diferentes formas que explicam o risco e o desastre, consequentemente, em um modelo holístico de interpretação. Da mesma forma, como alguém da economia para entender a crise do capitalismo, teria que entender a forma como o capital se desenvolve. Também direi que, para entender e responder à pergunta sobre o desastre como indicação da crise, teríamos que entender como o capitalismo em suas diferentes formas e também o socialismo, o comunismo e outros modelos levam à construção do risco e ao significado desse risco para o capital, para o trabalho, para os trabalhadores, para os informais, em termos de emprego e também para a construção de investimentos, e isso é um pouco fugir da questão, mas com uma lógica de continuidade e totalidade no tipo de análise que pretendemos.

\section{Construção Social do Risco}

Então, se hoje essa pergunta pode ser feita, há 50 anos ela nem poderia ser declarada. Uma época em que as interpretações de desastres como naturais, como construções físicas eram mais convenientes, intepretações "fisicalistas" como foi chamado por Hewitt (1983), nos anos 80, ou seja, desastre igual a terremoto, desastre igual a 
furacão, desastre igual inundação. E a sociedade era inocente e santa, e não contribuía muito para explicar que grau de dano ou quem sofreu esse dano. Se estivéssemos nessa situação ainda hoje, a questão sobre o capitalismo e a crise não teria relevância. O que teria relevância é se o capitalismo, o socialismo, o comunismo se desenvolveram em territórios atormentados por ameaças de grande impacto na sociedade e não importaria se fosse capitalista, socialista ou comunista, haveria danos e perdas e seria explicado pela quantidade e magnitude do evento. Mas, superamos, estamos em um momento em que há um grande entendimento, embora ainda não traduzido em prática, do que chamamos de construção social de risco, que em termos simples nos remete à forma como a sociedade, seus diferentes níveis, componentes, famílias, indivíduos, Estado, setor privado, contribuem através das ações que tomam para a construção de uma condição que chamamos de risco de desastre.

Assim, a construção social do risco automaticamente nos permite, como modalidade de análise, perguntar se desastres são indícios da crise do capitalismo. Sem essa confirmação seria difícil fazer a pergunta. Então, todo esse tipo de pergunta decorre de um primeiro momento em que houve uma aceitação de que o desenvolvimento e os desastres estavam relacionados. No início, antes dos anos 80, principalmente, a relação ia de desastre para desenvolvimento ou em outras palavras, desastres têm impacto em um desenvolvimento consumado. Envolve desviar recursos para a reconstrução, destrói os meios de subsistência construídos de diferentes populações, e assim por diante. Mas, a partir do começo dos anos 80 e baseado nos trabalhos, principalmente, na Europa e na América do Norte, e de pesquisadores como Ken Westgate, Ben Wisner, e O’Keefe (1976). E toda a teoria da vulnerabilidade começou a ser fomentada com base em estudos de desenvolvimento na África, com seca e fome em particular, não diretamente sobre desastres.

No entanto, por derivação, chegamos ao tema do desastre e, nos anos 1980, tivemos a publicação de livros como o de Fred Cuny (1983), "Desastres e desenvolvimento", e em 1983, o trabalho de Hackman, Blakie e a Cruz Vermelha Sueca que produziu aquela famosa frase de que desastres são processos de desenvolvimento incompletos e que mais tarde foi seguida por outros, com outras nomenclaturas, mas com a mesma mensagem: "que desastres e o risco que os precedem nascem no próprio processo de desenvolvimento." Em seguida, o Global Assessment Report das Nações Unidas, na sexta edição até agora, usou a noção de desastre como resultado de Skewed Development. Skewed em inglês, que não sei qual é a tradução mais apropriada, significa depravado, não alinhado corretamente, incompleto. Em seguida, toda a construção social do risco foi alimentar a vulnerabilidade com essas discussões de desenvolvimento com desastres. E assim estamos avançando para uma visão de construção social de risco e em que todo esse debate de questões de fundo que aparece no livro de Blaikie et al., em 1994, e que eles chamam de "drivers of risks", impulsores de risco, base de muitas interpretações de como o risco é socialmente construído. 
Se olharmos a partir dessa perspectiva para a noção de capitalismo, risco e desastre, há um fundo ideológico que é a base do capitalismo como um modo de produção, como um método de direcionamento do desenvolvimento da sociedade e que significa, em termos de processos concretos, que são impulsionadores de risco. Tais impulsionadores de risco são transferidos, sob certas circunstâncias, em condições de risco na sociedade. Então, está em toda parte. A habilidade de entender como o risco foi construído e, consequentemente, quando esse risco atinge as condições do desastre dado, qual seu papel e como ele indica uma relação com a crise do capitalismo baseia-se, na minha perspectiva, na compreensão do processo de construção social do risco.

\section{Riscos Sistêmicos}

Mas há outra questão que vou levantar e que deve ser considerada. Porque é muito fácil falar sobre desastres como indicações de algo, ou desastres como um reflexo de algo, ou desastres como um produto de algum processo. No entanto, hoje, estamos em uma complicação absoluta sobre o que seria desastre e como se expressa. Assim, com o Marco de Sendai, há uma ênfase em aumentar a importância das ameaças biológicas e tecnológicas. Insiste-se nas noções de multiameaças, ameaças complexas, ameaças concatenadas. Insiste-se em trabalhar na questão do risco sistêmico, não um risco referido a determinados ativos, como uma ponte, um edifício, uma comunidade. Estamos no mundo da sistemática: as relações entre as partes e como ela é transmitida, também estáveis no mundo das discussões sobre grandes, pequenos e médios desastres, que já foram indicadas pela ideia de risco extensivo, risco intensivo, e agora estamos diante da escala de impacto e concretude do desastre, muito no debate do risco sistêmico. Elas surgem precisamente por causa de um fenômeno global.

Em 2008, a crise financeira transmitida ao mundo por falhas de um único elemento do sistema financeiro em que o Estado não cuidava da sistemática e apenas controlava os ativos, um a um. Concepção da sistematicidade foi seguida pela insistência em compreender a mudança climática globalizada, com impactos em lugares que não tinham nada a ver com a criação das condições de ameaça, e assim por diante. E hoje temos o COVID, a maior expressão desde 1918 de uma pandemia que afeta o mundo e é transmitida pela forma como o capitalismo se desenvolveu com a internacionalização, a globalização, a facilitação da comunicação, e assim por diante. Então, quando falamos de desastres como sinais de crise do capitalismo, de que desastre estamos falando? Porque eventualmente acabaremos com a ideia de que tudo que altera a ordem cotidiana é um desastre. Mas se voltarmos a um terremoto no México e dissermos que contribui para a crise do capitalismo, seria uma resposta muito diferente dessa, e se o COVID-19 contribuísse... é uma manifestação ou indicação? E aqui, adoro ser controverso: não fechar o "chinamo", como dizem na América Central, com declarações contundentes.

Voltemos ao centro de análise. Bem, nós pegamos o capitalismo. Sabemos que o capitalismo passou por seus múltiplos estágios ao longo da história e que a última fase em seu nível mais global como explicação é o neoliberalismo que, dos anos 80 em 
diante, se desenvolve em resposta ao keynesianismo e ao estado de bem-estar. A crise do final dos anos 70, e assim por diante. Mas esse neoliberalismo tinha expressões e relações com outras facetas como a globalização, o capitalismo financeiro e continua em transição, o que hoje se fala do capitalismo cibernético como a próxima fase, como resultado do que está acontecendo. Assim, a questão das indicações, desastres como indicações, indicadores de desastres exige que desagregamos o significado e a realidade do neoliberalismo como prática. E depois disto, é preciso relacioná-lo com os fatores de risco que emergem na prática dessa ideologia particular em termos de economia.

Então, sem entrar em todos os detalhes que se poderia dar. Estamos falando de um sistema de pensamento construído por Von Mises (1949), na década de 40, e é retomado por Friedman e por muitos outros autores e, assim por diante, no qual a mão invisível do mercado e o mercado reinam, em que o indivíduo e o privado são superiores ao coletivo e ao Estado. Em Milton Friedmann, as facetas do desenvolvimento são expressas através desse neoliberalismo como a expressão mais moderna do capitalismo e hoje o tema do declínio do neoliberalismo é ouvido em muitos lugares, ou seja, a necessidade de transformação e transição. Agora que a transformação, ou transição, parece ser por falta de alternativa e alguém disse uma vez que os modelos já estão acabando, o keynesianismo, neoliberalismo, e assim por diante. Qual é a novidade? Qual o modelo? Estamos diante do declínio do neoliberalismo e da construção de um novo tipo de capitalismo e, consequentemente, que relação terá com a criação de condições que contribuam para risco e desastre.

\section{Vulnerabilidades singulares e complexas}

De forma analítica e cientificamente falando, teríamos que passar das características do que chamamos de causa, às características do efeito que seria risco e desastre. E isso teria que ser feito singularmente a partir de uma análise desses componentes que ainda são úteis de considerar. Embora eles devam ser muito mais integrais na concepção do que chamamos de exposição, vulnerabilidade e até ameaça em sua expressão, o que chamamos de sócio-natural, ou seja, a expressão da criação de ameaças, que não é natural porque se baseia na intervenção social no meio ambiente, criando ameaças que parecem ser naturais, mas que são induzidas pela sociedade, desmatamento que leva a enchentes e deslizamentos de terra, corte de manguezais nas costas, o que leva à erosão costeira, destruição da infraestrutura etc. Então, você teria que relacionar um com o outro. E o que sabemos além da avaliação de ativos, análise de risco sobre o significado do risco? Como o risco é internalizado nas decisões de diferentes atores sociais?

Em outras palavras, e exemplificando, sabemos que temos que estudar mais o mercado de terras urbanas na América Latina, que é $82 \%$ urbana e crescente, e a forma como está refletido no crescimento do capital e na especulação urbana e como se expressa na segregação socioespacial e no crescimento de bairros, favelas e informalidade, desigualdade, exclusão e pobreza, e assim por diante. Mas também deve estar relacionado à corrupção: a corrupção nasce no coração do capitalismo ou é comum 
a todos os sistemas econômicos? Pois sabemos que a corrupção e o traficante de drogas são criadores das cidades hoje. Vá ao Panamá, por exemplo. E sabemos que há a lavagem de dólares que também cria cidades. Assim, com a exposição tanto do capital quanto do trabalhador, a informalidade opera de forma a criar e constituir as condições de risco na cidade. Com vulnerabilidade também. Mas para entender a complexidade da vulnerabilidade dou o exemplo de como o capital, muitas vezes, está conscientemente localizado em áreas expostas e é até construído em condições de vulnerabilidade, que, no entanto, é absolutamente consistente com seu objetivo de aumentar o lucro em um modelo de integração econômica e transnacionalização e globalização. Não sei se se lembram das inundações na Tailândia do rio Chao Phraya em 2011, onde a Honda e a Toyota, empresas multinacionais japonesas perderam US\$1,7 bilhão em danos diretos, pois estavam localizadas no local da planície de inundação. Por que eles estavam localizados na planície de inundação? Várias razões poderiam ter contribuído para isso relacionadas com o funcionamento do capitalismo hoje. Primeiro, a competição de espaços de territórios de nações para atrair capital internacional e até mesmo a doação de instalações para o local. Assim, essas empresas foram liberadas do pagamento de impostos locais, ou impostos nacionais, para localizá-las em uma área que criou empregos para as pessoas de Bangkok, além de terem acesso muito fácil ao mar, porque estavam perto dos principais portos. Portanto, há uma lógica de como entender o risco que não é aquele que um tecnocrata entenderia. E o capital ganha porque finalmente entra em jogo, que é muito típico do capitalismo, do que chamamos em inglês de moral hazard, a ameaça, o risco moral. $\mathrm{O}$ que significa que atores individuais coletivos criam risco, mas não sofrem o mesmo risco, e quando perdem são resgatados pelos governos, pelas companhias de seguros, e assim por diante. Isso é precisamente o que aconteceu com a Honda e precisamente o que aconteceu com Fukushima, no Japão, onde o governo japonês, para o prestígio destas empresas, resgatou-as. Da mesma forma como o governo dos EUA resgatou o sistema financeiro com investimentos de seus impostos, "nossos impostos". Então, o risco é complicado em sua manifestação.

Não quero ir mais fundo porque o que estou dizendo é que se entendermos, tentarmos entender o significado de risco no processo de desenvolvimento, hoje em dia, em modelos de transnacionalização, de globalização, eles se manifestam de maneira completamente diferente das economias autônomas com pouco comércio internacional. Tal fato indica que poderiam sofrer o dano e não sofrer qualquer perda de lucro porque, em um sistema mundial de pontos de produção, o sistema iria absorver o dano, coletar seguros, receber o apoio do Estado e continuar. Antes não era assim. $\mathrm{O}$ capitalismo superou fronteiras e riscos, mesmo com todo o protecionismo que existe.

\section{A pandemia da COVID-19 como desastre}

E o último ponto: A COVID-19 foi legitimamente interpretada como um desatre ou catástrofe, mas não é um terremoto no México, não é um desastre associado a um terremoto no México, por exemplo. E se as perguntas sobre crises do capitalismo 
referiam-se a eventos cada vez mais globais, que tocam extensivamente todos os países, revela-se que a COVID-19 não nos ensina muito, não há lições. O que existe é uma exposição de situações que já existiam e que já tínhamos falado antes. O papel da desigualdade, da pobreza, da exclusão, da marginalização na falta de coordenação, da ruptura dos atores institucionais que não permitem que o tema das mudanças climáticas seja trabalhado com a gestão do risco de desastres, porque são como campos de caça entre diferentes agentes e não há troca, e assim por diante. Não é isso? Então, vem a COVID-19, um novo desastre, e vem a mudança climática, outro, que vai gerar problemas de diversas maneiras.

Em conclusão, não respondi se os desastres são uma indicação da crise no capitalismo. Deixo em aberto se forem indícios de crise em qualquer modelo, onde não há consideração dos elementos básicos e mecanismos que constroem riscos. E, consequentemente, a questão do que também aconteceu em termos de destruição ambiental, mudanças climáticas. Se o capitalismo pode reformar, seguir em frente, levar em conta e resolver esses problemas ambientais, mas sem mudar o modelo e os diferentes desenvolvimentos. Não estou discutindo nada em nenhum modelo de desenvolvimento. Parece-me que todos eles são fatais. Acho que posso me referir a mim mesmo, à minha fazenda para cultivar frutas e esquecer os outros.

Não sei se confundi mais do que esclareci, mas gostaria de deixar uma série de perguntas e convidar a nova geração de pesquisadores a voltar ao título deste artigo: seriam os desastres índicios da crise do capitalismo? E analisar, em profundidade e com muitos economistas, qual o significado disso para a pesquisa. Não uma alusão intuitiva de alguém que conhece mais ou menos o assunto, mas de quem sabe os detalhes do que precisa ser analisado. 


\section{Referências}

HEWITT, K. Interpretations of Calamity. London, UK. Allen \& Unwin, 1983.

O'KEEFE P., WESTGATE K., WISNER B. - "Taking the naturalness out of natural disasters", in Nature, 260, p. 566-577, 1976

CUNY, F. C. Disaster and Development. Oxford: Oxford University Press, 1983.

BLAIKIE P, CANNON T, DAVIS I, WISNER B. At Risk: Natural Hazards, People, Vulnerability, and Disasters. London, UK: Routledge,1994

MISES, L. von. Human Action. London: William Hodge, 1949. 